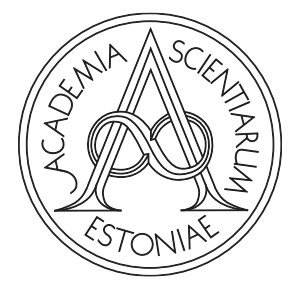

Proceedings of the Estonian Academy of Sciences, $2021,70,4,453-460$

https://doi.org/10.3176/proc.2021.4.12

Available online at www.eap.ee/proceedings

MANUFACTURING ENGINEERING

\title{
Industry 4.0 readiness for the manufacturing sector in the Baltic Sea Region
}

\author{
Sara M. Bazaz , Sakari Penttilä, Mikael Ollikainen, Juho Ratava and Juha Varis \\ LUT University, P.O. Box 20, FI-53851 Lappeenranta, Finland
}

Received 15 June 2021, accepted 16 July 2021, available online 4 November 2021

(C) 2021 Authors. This is an Open Access article distributed under the terms and conditions of the Creative Commons AttributionNonCommercial 4.0 International License (http://creativecommons.org/licenses/by-nc/4.0/).

\begin{abstract}
This study provides data and analysis on the state of digitalization of the manufacturing industries in the Baltic Sea Region. The compiled matrix contains entities on seven fields of operation and lists ten service and technology areas mapped from Denmark, Estonia, Finland, Latvia, Lithuania and Poland. A comparison of the collected data estimates the level of digitalization as well as identifies potential strengths and weaknesses by region. The available support structure is analysed to find potentially suitable partners to improve the level of digitalization in the enterprises of a region. Furthermore, the strength areas of each country are compared to weak areas to develop a roadmap to improve the readiness for implementation and use of Industry 4.0 functionality and tools. Examples are provided on the generation of a Business-to-Business (B2B) focused platform to improve the level of technologies and services in use, an example is also presented to identify and implement a use case based on an identified need.
\end{abstract}

Key words: manufacturing technology, digitalization, Industry 4.0, Baltic Sea Region.

\section{INTRODUCTION}

The manufacturing industry is rapidly digitalizing. Modern communication technologies, traditional automation and flexible automation (robotics) boost availability, flexibility, reliability and maintainability in the manufacturing industry [1,2]. While a heavily computerized process enables delivery of affordable high-quality products, taking full advantage of the production technologies requires also digitalized support systems in other parts of the manufacturing company's business and does cause some pressure on the business model [3,4]. Digitalization allows companies to plan and measure their performance $[5,6]$. In addition to potentially autonomous manufacturing as well as analysis of operations and even automatic improvement of operations, well-implemented Industry 4.0 digital manufacturing benefits employee collaboration, connectivity and productivity $[7,8]$. These allow

* Corresponding author, sara.moghadaszadeh.bazaz@lut.fi enhancing the supply chain and enable new capabilities, possibly up to customized production. As a challenge, the manufacturing industry is small and medium-sized enterprise (SME) dominated and resources to select and implement new technology in the manufacturing process are sparse in such companies $[9,10]$.

This study combines a set of data collected by a questionnaire and interviews with a survey of companyprovided manufacturing and support services. The latter survey relies mostly on publicly available data but also includes some interviews. The data shows a sample of the existing level of digitalization in the studied region of the country, available services, and potentially "simple" points of improvement where available technology has a low adoption rate. Local availability is also considered a matter of importance for equipment that might need specialized maintenance services. Finally, a few potential applications of the collected data are shown in the form of a B2B platform to keep the data complete and up to date, and a sample use case is generated. 


\section{METHODS}

The digitalization structure and readiness for Industry 4.0 in metalwork manufacturing was evaluated for six countries in the Baltic Sea Region: Denmark, Finland, Estonia, Latvia, Lithuania and Poland. In the case of some of the countries, a specific region was emphasized. In Denmark, the region of Funen was evaluated. In Latvia, the regions of Riga and Kurzeme were analysed. In Estonia, the regions of Harju, Viljandi, and Ida-Viru were evaluated. In Poland, the regions of Kuyavian-Pomeranian, Mazovian, and Lesser Poland were studied. In Lithuania, the regions of Vilnius, Kaunas, Klaipeda, and Šiauliai were analysed. Finland evaluated most of the industrial regions all over the country. In the first phase, the state of digitalization - the number of digitalized products and services in use in the manufacturing industry - was surveyed by a questionnaire and interviews in each country. In the second phase, the availability of various services and technologies was surveyed based on public sources such as web pages, and based on interviews on where the manufacturing companies in the country have acquired the technologies they utilize.

\subsection{State of digitalization in companies in each country}

The adoption of different digitalization technologies and services was surveyed by an online questionnaire and company interviews. The categories in the questionnaire were based on the ANSI/ISA-95 classification of systems, producing ten different categories, with five questions each to survey the rate of adoption of technologies in the category. This resulted in a total of fifty questions on the level of digitalization divided into the following categories:

1. Customer Relationship Management (CRM);

2. Technology planning, Product Lifecycle Management (PLM);

3. Vertical and horizontal value chain integration through computer networks;

4. Computer-Aided Quality Control (CAQC);

5. Production monitoring and Manufacturing Execution System (MES);

6. Production planning and Enterprise Resource Planning (ERP);

7. Cyber-Physical Systems (CPS);

8. Logistics and Warehouse Management Systems (WMS);

9. Computerized Maintenance Management Systems (CMMS);

10. Quality assurance and Laboratory Information Management Systems (LIMS).

Each question inquired if a specific component, technology, or service was in use in the company, with options of "Not existing", "Partly used", and "Totally used" interpreted as the weight of $0 \%, 50 \%$, and $100 \%$, with the arithmetic mean forming an estimate for the adoption of technologies in that category. The country results were calculated as a mean of the answers of individual companies. It was expected that individual answers may have some inaccuracies due to how the questions would be interpreted, and the scale is rather coarse, but with a sufficient amount of qualitative answers, a quantitive analysis can be performed.

\subsection{State of digitalization support in each country}

The availability of digitalization technologies and services was surveyed in the above categories in each country. This was performed chiefly as desk research by searching public information about companies operating in seven different fields or functions necessary for the smooth operation of the modern manufacturing industry. Additional knowledge of services used may also have been gained by interviewing industry experts. The different entity groups surveyed are:

1. Engineering (manufacturing or mechatronic systems designers, manufacturers and vendors);

2. IT (providers of supporting software, hardware and services, including software as a service (SaaS) and cloud services);

3. Competence centres (project or program support, typically skill-based or network-based);

4. Educational institutions (vocational schools, universities of applied sciences, universities);

5. Digital innovation hubs (social communities or research centres providing expertise on technology trends, knowledge and strategic innovation management, and acting as start-up incubators);

6. Industrial associations (employee and industry business support);

7. Public organizations (research organizations and various development organizations).

Based on this information, a support structure matrix was compiled indicating the availability of know-how, technologies and services in each country. Notably, an individual entity can fit into one or more categories (such as an educational institution assisting in designing systems in addition to providing an educated workforce).

\subsection{Comparison of the level of digitalization of companies in the countries of the Baltic Sea Region}

The availability of digitalized technologies and services in different countries, surveyed as described in 2.1, was compared between the countries. The data set consists of 64 entities in Denmark, 27 in Estonia, 85 in Finland, 
62 in Latvia, 60 in Lithuania and 71 in Poland. This mapping of providers assists in finding providers to improve the level of digitalization and is indicative of the digitalization readiness in each country.

Some specializations may be apparent, such as a vendor of a management suite being marked as an IT company providing ERP, MES, and PLM services but no other information technology and communications. There may also be overlaps, such as an engineering and IT category company providing PLM, CPS, and LIMS is indicative of a robotics vendor also providing supporting products or services. Naturally, some educational institutes and research hubs are active in a wide variety of fields. The differences in the readiness for Industry 4.0 were presented and the lack of required digitalization level in each category between the companies was evaluated.

\subsection{Support functionality analysis of the Baltic Region}

Support functionality in each country was analysed by comparing the support structure matrix with the adoption level of digitalized technologies and services. Manufacturing technology companies were categorized by their Nomenclature of Economic Activities or NACE code [11]. In addition to 2.3, the differences in the support structures between the countries were evaluated. Based on the rate of adoption, potential areas for improvement were pointed out. The improvement areas were compared to the support structure matrix to detect if the necessary support was available from within the country or from the other countries in the study. The roadmap to increase the level of digitalization and readiness for Industry 4.0 implementation in the Baltic Sea Region was presented.

\section{RESULTS AND ANALYSIS}

The collected data set represents an incomplete but representative sample of the activities in the country. Additionally, the size of an entity is not apparent in the sample, which may cause some skew in the results. The distribution of the entities surveyed for the support structure is presented in Fig. 1. While the methodology applied to all countries is effectively the same, the samples are dissimilar. Denmark, Estonia and Poland have a higher share of engineering category entities. Estonia and Denmark have fewer IT companies, whereas Poland has a very high share of companies providing at least some IT services. Estonia has a high share of educational institutes, competence centres, and digital innovation hubs, suggesting a high level of communal support. While engineering and IT companies are necessary to acquire the technologies and services as well as to gain competence, supporting entities are necessary. Poland and Denmark have relatively few educational institutes listed in the sample; Finland, Poland and Denmark have few competence centres. No digital innovation hubs were listed in the study for Poland and few for Denmark. Estonia has an especially high share of public organizations, with Finland and Denmark having few.

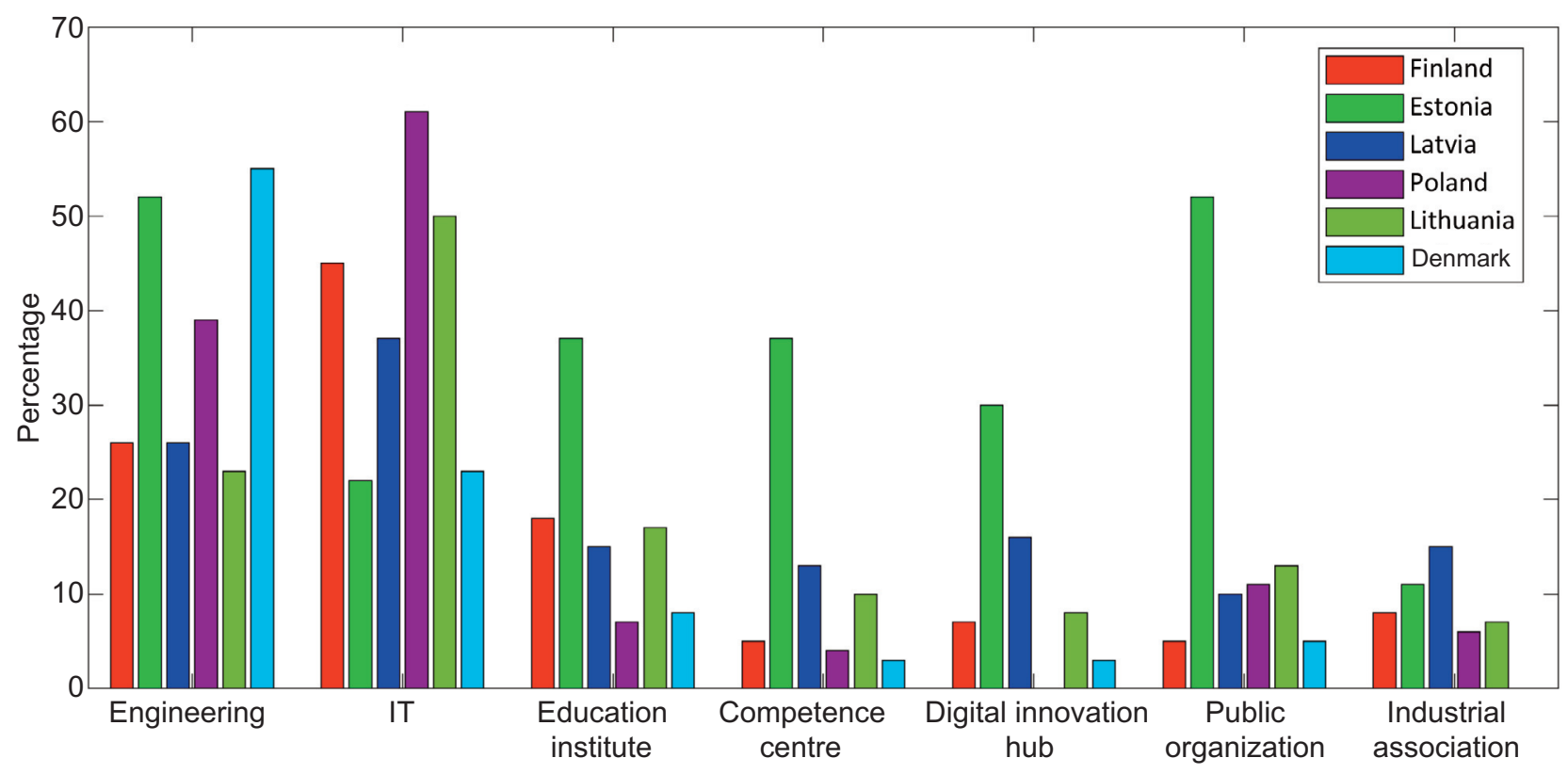

Distribution of the number of entities in service and technologies

Fig. 1. Distribution of manufacturing relevant entities in each country. One entity having divisions in different fields means that totals may add up to over $100 \%$. 
Latvia and Estonia list a higher number of industrial associations, whereas Denmark had none in the sample.

Considering the activities of the entities, there is ultimately relatively little overlap. In all the countries, education institutes provide some kind of engineering and IT category services. Estonia, Latvia, Lithuania and Poland are also integral competence centres and digital innovation hubs. The availability, share and distribution of individual technologies or services is shown in Fig. 2. Notably, PLM (Product Lifecycle Management), VH (Vertical and Horizontal value chain integration through computer networks), CAQC (Computer-Aided Quality Control), MES (Manufacturing Execution System), and CPS (Cyber-Physical Systems) are more common whereas CRM, ERP, LIMS, and maintenance technologies are less common.

Specifically, Product Lifecycle Management services are common in Finland, Estonia and Poland. Estonia has the highest share of over $50 \%$ of surveyed entities offering some kind of competence in integrating computer networks, with Poland and Denmark having the lowest level of adoption. Poland is a notable outlier in ComputerAided Quality Control, having a relatively low level of availability. Denmark has a higher level of services offered in Manufacturing Execution Systems, with Finland showing the relatively lowest availability. Denmark takes the lead in Cyber-Physical Systems, with other countries having a good level of adoption. The high share of CPS services in Denmark can be explained by the region of Funen being a notable centre for robotics development in Denmark.
In Customer Relationship Management, Estonia and Finland have the highest level of support, with apparently few offerings in Denmark. These functions may be included in ERP systems, which appear to enjoy good support in Estonia and Finland, some support in Lithuania, but surprisingly low support otherwise. For Warehouse Management Systems, all partners have a similar rate of adoption; some functionality may be included in ERP. Denmark seems to have a lower rate of WMS services or products offered. In Laboratory Information Management, Finland and Estonia seem to have a higher level of digitalization than the other partners. Finally, maintenance systems appear to enjoy a better level of support in Finland than elsewhere.

Overall, Estonia and Finland seem to have a high degree of readiness for Industry 4.0, with a comparative focus on customer and customer satisfaction-oriented systems, services and technologies such as ERP, CRM and LIMS. The Danish sample of the study suggests significant competence in manufacturing automation. Lithuania appears to be having a slightly higher level at many of the less adopted systems compared to its neighbours.

Despite the lack of information on company size and volume of products offered, based on the collected data, one might consider a share of companies under $15 \%$ in service to warrant some concern, with under $30 \%$ indicate some room for improvement on availability. Maintenance systems are either not listed separately or then the availability of digitalized maintenance is low - something that may be worth some concern when companies might not have the ability to maintain high-tech systems

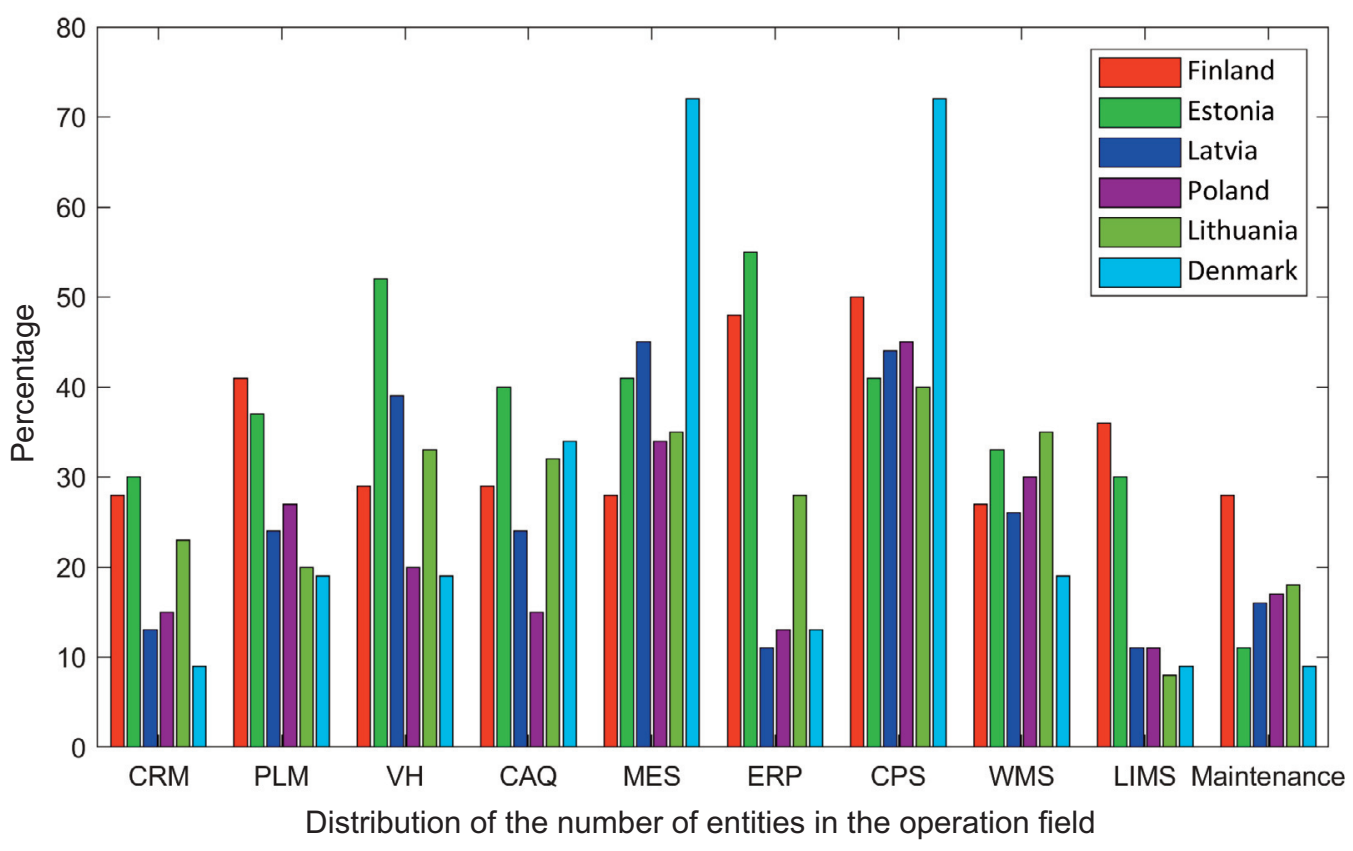

Fig. 2. Cross-country comparison - supported services and technologies (percentage of entities listed). 
themselves. Other than Estonia and Finland, ERP, CRM, PLM, and LIMS seem to have room for improvement. The Danish sample is high in CPS, MES and CAQ, and low in other technologies. This may be due to a high number of robotics companies in the sample. Other notable opportunities for improvement include $\mathrm{VH}$ and $\mathrm{CAQ}$ systems for Poland and CAQ systems for Latvia.

Figure 3 demonstrates the company's field of activities that are studied in each country. These activities are based on the NACE code. The NACE codes are a European industry standard classification system that provides a framework to classify the collected data in the range of statistics in economic fields. Any statistical study needs to be described in terms of systematic nomenclature. The systematic nomenclature classifies the statistics studied into different categories and sub-categories. This research used the main set code to classify the company's field of activities. The most important fields defined in the NACE code 2005 in this project are:

1. M80: Education institutes.

2. O91: Activities of membership organization, which includes activities of business, employers and professional organizations, activities of trade unions, and activities of other membership organizations.
3. K72: Computer and related activities, which includes hardware consultancy, software consultancy and supply, data processing, database activities, and other computer-related activities.

4. DK29: Manufacture of machinery and equipment, which includes manufacture of machinery for the production; manufacture of engines and turbines, pumps, valves, bearing, gears, cooling and ventilation equipment; manufacture of agricultural and forestry machinery, tractors; manufacture of machinery for mining, quarrying and construction; and manufacture of other special-purpose machinery.

5. DJ27: Manufacture of basic metals, tubes, cast iron tubes, steel tubes, cold drawing, cold rolling of narrow strips, cold forming or folding, wire drawing, aluminium and copper production, and casting metals.

6. DJ28: Manufacture of fabricated metal products, with sub-process in manufacturing of structural metal products, tanks, reservoirs, containers of metal and central heating, steam generator, tools, fasteners, screw machine products, chain, and springs. Treatment and coating of metals, and general mechanical engineering.

7. G51: Wholesale trade and commission trade.

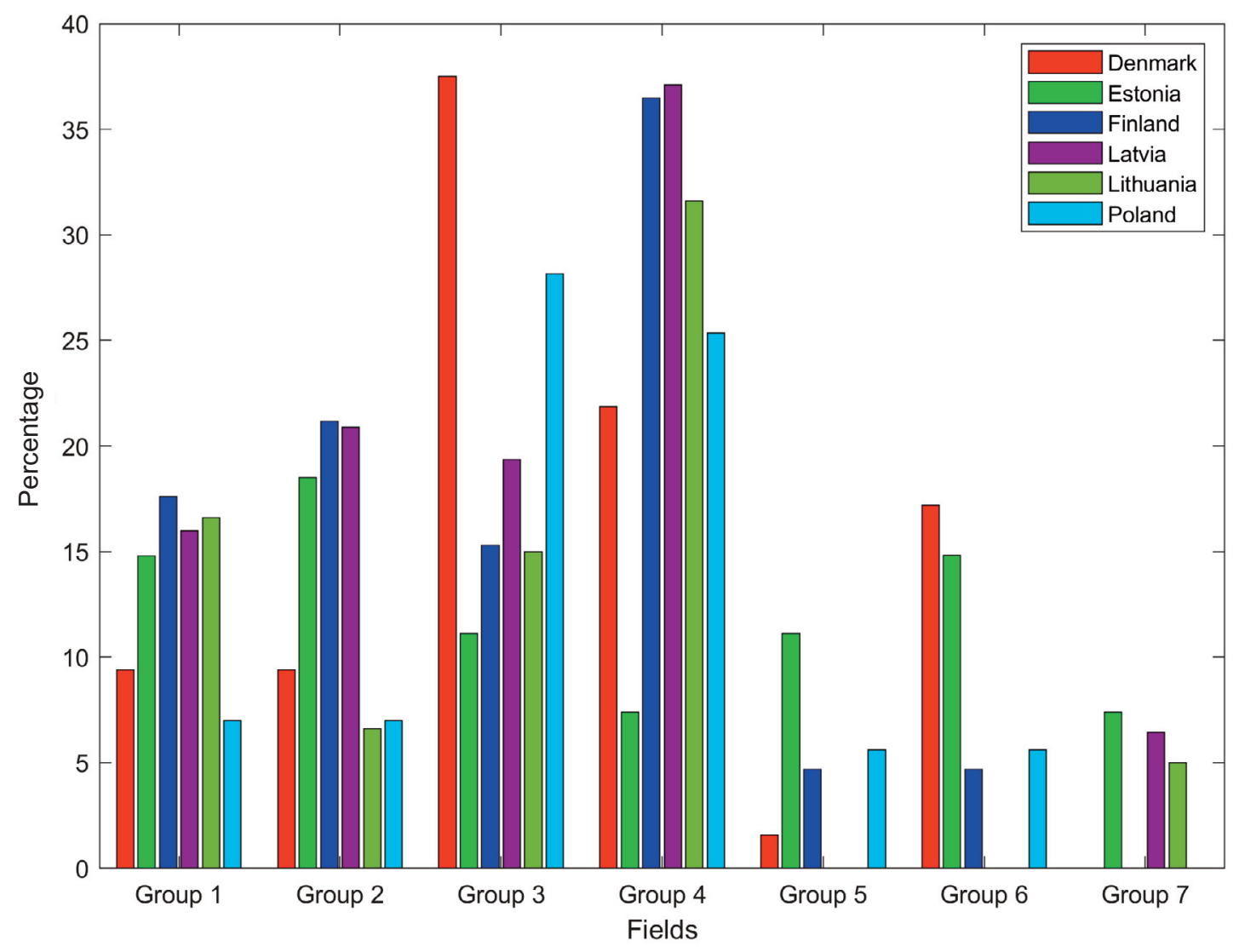

Fig. 3. Comparison of the fields of activity in each country. 
In Fig. 3, there are seven groups of activities. Group 1 includes educational institutes as well as research and development centres. Group 2 covers all the support organizations such as digital innovation hubs, competence centres, public organizations and industrial associations. Group 3 comprises any active companies in production, mechanical engineering, and machinery equipment. Computer service providers which provide software, hardware, or any data processing system are included in Group 4. Entities active in basic metal manufacturing are in Group 5. Group 6 covers manufacturers of fabricated metal products and Group 7 represents entities engaged in the complete sale of machinery and machine tools.

Figure 3 also shows the percentage of the involved activity in each field. Analysing Figs 2 and 3 indicates the percentage of providers in each field and how data were gathered in each country. For instance, entities mostly belong to Groups 3 and 4, which shows how high percentage of the entities are providers of computer-related services and how high percentage belongs to manufacturing providers in each country. Denmark has the most providers in manufacturing machinery products while Finland and Latvia have the most providers in computerrelated activities including software and hardware. Almost $20 \%$ of the entities in Estonia, Finland and Latvia are the support organizations for industry and employees. All partners except Latvia and Lithuania distinguished between the manufacturing of machinery equipment and the manufacturing of basic metals and fabricated metals. In Denmark, Estonia and Finland 17\%,15\%, and 5\% of the entities operate in the manufacturing of fabricated metals respectively, while $37.5 \%$ of the entities in Denmark, $11.1 \%$ in Estonia and $15.3 \%$ in Finland are manufacturers of mechanical machinery and equipment. Among all the countries in this study, Estonia has the highest number of providers in the manufacturing of basic metals. This statistical outcome could assist Latvia and Lithuania in finding a provider for their specific needs in the manufacturing of basic metals and fabricated metal products from their neighbouring countries.

\section{POTENTIAL APPLICATIONS}

This study was carried out among six countries in the Baltic Sea Region to help these countries to identify their needs to update the level of digitalization in metal manufacturing and the mechatronic industry in 20202021. Two methods were studied in this project for implementation - the functionality analysis matrix and the gathered statistical data. Developing the matrix as a B2B platform and extracting a use case from the outcome serves to fill the necessary gap in the industry and find the solution with the assistance of the other partners.

\subsection{B2B platform}

Publishing the results in scientific papers is a way to share and use the outcome of the project only for partners. However, with rapid progress in automation and the digital industry (Industry 4.0) these data need to be constantly updated. Using the gathered data in this project as an initial database to create a B2B platform is suggested to connect users and consumers. The B2B platform is an environment to provide transaction and communication from one business to another to present the available competence and request new competence. Each member in the platform can be either a customer, a service provider, or both simultaneously. This platform can be extended to attract members from other countries in Europe, serving as a practical reference to find partners for collaboration in metal manufacturing and the mechatronic industry.

\subsection{Use case creation}

It is suggested that the data extracted from the interviews, the functionality structure matrix and the relationship matrix guide analysers and experts to find the gap in services and technologies in their region. Potential use cases for the adoption of relatively simple new technology can be identified by comparing available technology with the low adoption of specific technologies. This section presents how to find a gap in on-demand services and technologies in Finland and define a use case to study with the other partners in this study to provide a solution for SMEs in South Finland.

As Fig. 3 presents, among the 85 entities in Finland, only $5 \%$ of the companies are active in manufacturing fabricated metal products. On the other hand, Fig. 2 shows that computer-aided quality control and maintenance have almost 30\% share in digital services in Finland. When interviewing SMEs in Finland, the needs were expressed for measurement, data collecting and analysing in regard to manufactured products, especially in welding. As such, it demonstrates new capabilities by collecting and analysing camera data, as well as how selecting, installing and applying the technology might help improve the capabilities in this field.

Modern optical sensors such as laser triangulating sensors are capable of measuring individual points, lines, or shapes by measuring when a beam of light impacts a piece and then combining these measurements. A commercially available sensor is combined with a similarly available software suite, allowing thus the simple modelling of objects. In the case of welding, it is possible to calculate stress in the joint and potentially detect the more major cracks. Furthermore, based on stress, it is possible to estimate fatigue life. This allows to greatly simplify critical functions for weld quality management and 
structural safety. In addition, automating either parts or the entirety of a measurement with a non-contact method greatly simplifies the measurement process. Storing the measurement enables to capture and associate 3D features and compare those to Welding Procedure Specification (WPS) and potentially to other requirements. Traditional manual measurement and classification of features such as some types of cracks, bead height, and wear are strongly dependent on worker experience and fatigue. Automation should increase reliability by reducing the effect of subjectivity. In the last decades, the noise tolerance and accuracy of optical methods have improved. Computing capabilities allow for near real-time results.

In inspection of heavy industries, combining the previous aspects should lead to notable savings and competitive advantages, though standards still require specific methods of inspection and do not yet include new technologies. However, early quality management reduces waste when defects are detected before the final inspection, especially when the final inspection is performed by an external auditor.

The first step of the solution is compiling a database of available inspection systems in the European market. This database contains details of the systems, prices, and application fields. Then instructions and best practices on how to integrate a new device into production processes are developed in this use case. The final phase of the solution is organizing a regional seminar and webinars for targeted companies and presenting methods of inspecting, measuring, and analysing data in different applications and environments.

\section{DISCUSSION}

The reliability of the study is dependent on the data gathered. The data does not represent the whole view of the companies or the service providers. Therefore, the results of the study do not present the absolute level of the digitalization of the companies in each country. However, the experts in manufacturing technology have conducted the surveys and questionnaires in each country. Therefore, the study presents a brief but easily generalized overview of the level of digitalization and support structures in the Baltic Sea Region.

The results of the study can be applied in practice by acknowledging and sharing the information between the countries via, e.g., a digital platform offering easy access to companies for the information. Companies can find the suppliers, vendors and knowledge about the Industry 4.0 benefits as well as practical steps on how to apply the theory in practice. Thus, the level of digitalization can be increased in the companies. By increasing the level of digitalization in companies, Industry 4.0 can be further implemented in practice. This can not only enhance the viability at the company level but also at the national as well as the EU level. However, the language barrier between the countries might affect the applicability as especially SMEs in Latvia, Lithuania and Poland are not using English as a common working language. Hence, translation process is required between the service providers to increase the effectiveness. For further study, a wider database of the levels of digitalization in the whole EU could be applied to increase the collaboration and potential competitiveness of the EU.

\section{CONCLUSIONS}

The survey about the digitalization level of the six countries in the Baltic Sea Region was conducted based on surveys and questionnaires. The resulting support structure matrix consists of seven operation fields and ten service and technology areas. The information was collected from typical and available entities in the industrial region. The results can be utilized to help the countries to develop a policy and identify their weaknesses and strengths in ten important and useful digital technology areas. The results of the support functionality analysis can be utilized to assist countries and their respective entities to collaborate with the other partners to enhance their digital level in the industry. Overall, Finland and Estonia have consistent availability in most services. The Danish robotics cluster is notable in the surveys. Denmark, Poland and Latvia are lacking some areas of services while Lithuania has the average share of the level of digitalization among the countries. Along with maintenance automation, CRM, ERP, and LIMS have the most potential to be improved to further improve the level of digitalization in the SMEs of the Baltic Sea Region. The outcome of this study is published as the initial data in a business platform. A use case is extracted from the questionnaires, the functionality analysis matrix and the relation matrix analysis to fill the industrial needs for SMEs in a region.

\section{ACKNOWLEDGEMENTS}

The authors would like to extend thanks to Tallinn University of Technology, IMECC, Machine Technology Center Turku, Odense Robotics, Liepaja State Technical School, Lithuanian Innovation Centre, Klaipeda Science and Technology Park and Toruń Regional Development Agency for performing the data collection in their respective countries and regions. This research received funding from Interreg Baltic Sea Region project "Innovation Framework for Challenge Oriented Intelligent 
Manufacturing (INforM)", grant number \#R078. The publication costs of this article were covered by the Estonian Academy of Sciences and Tallinn University of Technology.

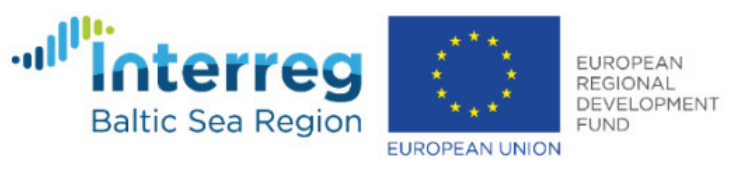

\section{REFERENCES}

1. Mahmood, K., Karaulova, T., Otto, T. and Shevtshenko, E. Development of cyber-physical production systems based on modelling technologies. Proc. Est. Acad. Sci., 2019, 68(4), 348-355.

2. Kangru, T., Riives, J., Mahmood, K. and Otto, T. Suitability analysis of using industrial robots in manufacturing. Proc. Est. Acad. Sci., 2019, 68(4), 383-388.

3. Qi, Q. and Tao, F. Digital twin and big data towards smart manufacturing and Industry 4.0: 360 degree comparison. IEEE Access, 2018, 6, 3585-3593.

4. Lõun, K., Riives, J. and Otto, T. Evaluation of the operation expedience of technological resources in a manufacturing network. Est. J. Eng., 2011, 17(1), 51-65.

5. Riives, J., Karjust, K., Küttner, R., Lemmik, R., Koov, K. and Lavin, J. Software development platform for integrated manufacturing engineering system. In Proceedings of the 8th International DAAAM Baltic Conference "Industrial Engineering”, Tallinn, Estonia, April 19-21, 2012. Tallinn University of Technology, 2012, 555-560.

6. Kaganski, S., Majak, J., Karjust, K. and Toompalu, S. Implementation of key performance indicators selection model as part of the Enterprise Analysis Model. Procedia CIRP, 2017, 63, 283-288.

7. Kolberg, D. and Zühlke, D. Lean automation enabled by Industry 4.0 technologies. IFAC-PapersOnLine, 2015, 48(3), 1870-1875.

8. De Carolis, A., Macchi, M., Negri, E. and Terzi, S. Guiding manufacturing companies towards digitalization a methodology for supporting manufacturing companies in defining their digitalization roadmap. In Proceedings of the 2017 International Conference on Engineering, Technology and Innovation (ICE/ITMC), Madeira, Portugal, June 27-29, 2017. IEEE, 487-495.

9. Bazaz, S. M., Penttilä, S., Ratava, J., Ollikainen, M. and Varis, J. SMEs' support functionality analysis based on statistical analysis. Procedia Manuf., 2020, 51, 960-966.

10. Roblek, V., Meško, M. and Krapež, A. A complex view of Industry 4.0. SAGE Open, 2016, 6(2). https://doi.org/10.1177/ 2158244016653987

11. Carré, H. Statistical classification of economic activities in the European Community. Publications Office of the European Union, Luxembourg, 2008.

\title{
Tootmissektori valmisolek Tööstus 4.0-iks Läänemere piirkonnas
}

\author{
Sara M Bazaz, Sakari Penttilä, Mikael Ollikainen, Juho Ratava ja Juha Varis
}

Antud uuring sisaldab andmeid ja analüüse Läänemere piirkonnas oleva töötleva tööstuse digitaliseerimise kohta. Koostatud maatriks sisaldab seitset tegevusvaldkonda ning käsitleb kümmet teenindus- ja tehnoloogiavaldkonda Taanist, Eestist, Soomest, Lätist, Leedust ja Poolast. Kogutud andmete põhjal hinnatakse digiteerimise taset ning tuvastatakse piirkonniti võimalikud tugevad ja nõrgad küljed. Analüüsitakse olemasolevat tugistruktuuri, et leida potentsiaalselt sobivaid partnereid, et parandada digitaliseerimise taset piirkonna ettevõtetes. Lisaks võrreldakse iga riigi tugevaid valdkondi nõrkade piirkondadega, et töötada välja tegevuskava parandamaks valmisolekut Tööstus 4.0 funktsioonide ja vahendite rakendamiseks ja kasutamiseks. Näiteid on toodud ettevõtetevahelisele ärirakendusele (B2B) keskendunud platvormi loomise kohta, et parendada kasutatavate tehnoloogiate ja teenuste taset. 